\title{
Implementation of Clinical Assistants in a Pediatric Oncology Department: an Activity and Clinical Time Release Analysis
}

Adroher, Cristina* ; Calvo, Celia; Pavon, Laura; Casadevall, Ricard; Alvarez, Esther; Marsal, Mariona; Lopez, Francesc; Morales, Andres

* Corresponding author

\section{Abstract}

Background: There is a high bureaucratic and administrative burden associated with health care tasks (test requesting, visits scheduling, supporting documents provision) that has historically largely fallen on health care professionals, which is one among the factors contributing to low job satisfaction and lower productivity. Incorporating new professional roles that help to better respond to the needs of both patients and professionals can increase the quality and efficiency of service provision.

Objective: To evaluate the impact of the clinical assistant's introduction in the Sant Joan de Déu Barcelona Children's Hospital's pediatric oncology department, in terms of displacement of activity loads carried out by this new professional role and the consequent time freed up for physicians.

Methodology: Observational and retrospective study using administrative data based on the analysis of the type of activity performed by clinical assistants and the measurement of the time freed up in favor of the physicians, based on in situ timekeeping, to approximate the potential skill mix productivity increase.

Results: Since its implementation in the pediatric oncology department, clinical assistants have performed 13,553 requests $(69.93 \%$ of the total), representing a total saving of 266.83 hours or 6.67 workweeks of 40 hours. They performed $74.25 \%$ of outpatient surgical requests in the oncology department, $87.5 \%$ of day hospital requests and $54.13 \%$ of total requests in the outpatient consultations area.

Conclusion: The introduction of clinical assistants in the oncology department could be efficient to the extent that it displaces a good part of the bureaucratic and administrative tasks previously performed by health care professionals. This delegation allows them to work more closely to the maximum of their competences and the physicians to have more time for higher added value clinical tasks. In terms of efficiency, this role change enables to optimize the clinical process, reducing the cost by $56 \%$ compared to the conventional model.

\section{Introduction}

The Spanish healthcare system is known for its good health outcomes, although it is far from other European countries in terms of healthcare productivity [1]. This may be partly due to the high bureaucratic burden associated with care tasks (request for tests, scheduling of visits, completion of supporting documents, etc.) which accounts for a significant number of working hours of medical professionals [2]. In turn, this is one of the factors contributing to their low job satisfaction and burn out $[3,4,5,6,7]$. A study conducted in the context of the British National Health Service suggests that $20 \%$ of the work of general practitioners is devoted to administrative tasks [8]. Other works point out that more 
than $75 \%$ of the professionals $(79 \%$ of nurses and $76 \%$ of practitioners) declare to be over-skilled to perform part of their work [9,].

At the macro or health policy level, the Spanish healthcare system (as well as other surrounding countries) is in a situation of professionals' shortage, this being one of the greatest challenges it faces. As a consequence, several approaches have been proposed to address the workforce gap. Studies point to any comprehensive solution combining several strategies including improving retention of professionals, incentivizing the competency growth of existing roles, maximizing current staff's efficiency, and creating new professional roles [10]. At the micro or organizational level, professionals are the primary agents of change within an organization. Improvements in care come, in part, from redefining the current role of practitioners, focusing on what brings value [11]. For this change to be effective, it is necessary to incorporate new professional roles into healthcare institutions that help to better respond to the needs of patients and healthcare professionals themselves. In the United Kingdom, some studies have proposed the implementation of multidisciplinary teams in primary and community care consisting of pharmacists, physiotherapists and management staff among others [12]. Other countries have introduced new professional roles such as clinical assistants, or expanded or modified the competencies of existing professionals, as is the case of advanced practice nurses [13].

Some evidence shows that support workers give good-quality and patient-focused care while they contribute to reduce the more qualified staff's amount of work. [14]. Other studies have estimated the potential increase in productivity of primary care physicians by quantifying the amount of time saved if they delegated tasks to other types of professionals, or they could be performed in an automated manner, showing between $25 \%$ and $77 \%$ of the tasks performed by these physicians could be delegated to other professionals, increasing their capacity to attend users by 41-98\% [15]. However, there is no specific evidence of the savings that the introduction of new professionals could entail in an oncology department.

In this context, the aim of this article is to evaluate the impact of the introduction of the clinical assistant role in the pediatric oncology department of the Sant Joan de Déu Children's Hospital, in terms of the workload's displacement due to this new professional role, and the consequent time freed up in favor of the physicians.

\section{Methodology}

The Sant Joan de Déu Barcelona Children's Hospital is the pediatric center of reference at the Spanish level and the first in oncology activity [16]. It was the first center in the state to introduce at the beginning of 2020 the clinical assistant professional role in the oncology department: two support professionals to the physicians who perform complementary tasks to the medical processes. Throughout the period analyzed, there have been up to 7 different administrative assistants who have provided support in requests to 35 physicians.

The clinical assistant is the patient's reference on administrative issues and is responsible for coordinating the different phases of the care process, making requests, scheduling tests and procedures as well as other bureaucratic tasks, among other functions, always acting under physician's delegation. This professional combines direct patient care tasks with back-office tasks. Their profile may vary according to the needs of each service, but they are mainly clinical documentation technicians or administrative staff with previous experience in the healthcare field. These professionals received specific training for three weeks, sharing a consultation with the physicians among others. 
The Lean methodology is based on the "elimination of operations that do not add value to the company's product or service from the viewpoint of the costumer" [17]. In healthcare, it is applied with the objective of reducing actions that do not generate added value from the patient's point of view. Based on this logic, this article calculates the time released by clinical assistants to physicians to approximate the increase in skill mix productivity [15]. For this purpose, the 19,406 requests made in the outpatient department (day hospital, outpatient consultations and outpatient surgical requests) in the period from February 1, 2020, to March 17, 2021 have been analyzed by comparing the number of requests made by physicians and clinical assistants. As a measure of the time needed to make a request, this article uses the approximation made by clinical assistants and physicians based on the in situ and systematic timing of each type of procedure.

Requests made by administrative staff who are not clinical assistants, nursing staff and resident physicians were excluded from the analysis since, for the time being, the clinical assistant mainly makes requests by delegation of the attending physicians. Likewise, physicians who made fewer than ten requests during the period analyzed and those who had made less than $5 \%$ of the requests through clinical assistants were excluded. Finally requests which can only be made by physicians, such as analytical tests performed after surgery or requests to the blood bank are also excluded.

\section{Results}

\section{Types of requests made}

Clinical assistants made 13,553 requests in the outpatient area, which represents $69.93 \%$ of the total number of requests subject to the study period $(19,381)$. Table 1 breaks down the administrative activity of the outpatient area according to the types of requests and their corresponding time spent.

Clinical assistants performed $74.25 \%$ of outpatient surgical requests and $87.5 \%$ of day hospital requests, this being the area in which this professional profile is most widely used (and whose requests consist mostly in laboratory tests). Regarding outpatient consultations, requests made by clinical assistants account for $54.13 \%$ of the total. Results show that the percentage of requests made, in relation to the total, varies substantially depending on its type. On the one hand, clinical assistants perform few interconsultations $(10.00 \%)$ and requests for laboratory tests (33.74\%), since these are still mostly performed by physicians. On the other hand, clinical assistants perform most diagnostic imaging requests (82.02\%), external tests (84.47\%) and complementary tests $(87.65 \%)$. 
Table 1. Activity and times summary.

\begin{tabular}{|c|c|c|c|c|}
\hline & Total & Clinical Assistant & $\begin{array}{l}\text { Seconds per } \\
\text { request }\end{array}$ & $\begin{array}{c}\text { Time released for the physician } \\
\text { by the CAs (hours) }\end{array}$ \\
\hline Surgery requests & 1274 & $946(74.25 \%)$ & 94 & 24.70 \\
\hline Day hospital requests & 8407 & $7356(87.5 \%)$ & & 138.17 \\
\hline Diagnostic imaging & 38 & $12(31.58 \%)$ & & 0.25 \\
\hline Magnetic resonance imaging (MRI) & 6 & $4(66.67 \%)$ & 98 & 0.11 \\
\hline Radiology (RX) & 8 & $1(12.5 \%)$ & 54 & 0.02 \\
\hline Echography (ECO) & 10 & $3(30 \%)$ & 52 & 0.04 \\
\hline Computerized Axial Tomography (CT) & 14 & $4(28.57 \%)$ & 74 & 0.08 \\
\hline External tests & 9 & $9(100 \%)$ & 74 & 0.19 \\
\hline Laboratory tests & 8338 & $7334(87.96 \%)$ & $60 / 98^{*}$ & 137.72 \\
\hline Referrals and interoconsultations & 22 & $1(4.55 \%)$ & 60 & 0.02 \\
\hline Outpatient consultation requests & 9700 & $5251(54.13 \%)$ & & 103.96 \\
\hline Diagnostic imaging & 2742 & $2249(82.02 \%)$ & & 48.82 \\
\hline Magnetic Resonance Imaging (RMI) & 1422 & $1158(81.43 \%)$ & 98 & 31.52 \\
\hline Radiology (RX) & 278 & $202(72.66 \%)$ & 54 & 3.03 \\
\hline Echography (ECO) & 758 & $656(86.54 \%)$ & 52 & 9.48 \\
\hline Computerized Axial Tomography (CT) & 284 & $233(82.04 \%)$ & 74 & 4.79 \\
\hline External tests & 676 & $571(84.47 \%)$ & & 11.74 \\
\hline Gammagraphy & 6 & $6(100 \%)$ & 74 & 0.12 \\
\hline Whole-body scanning & 186 & $183(98.39 \%)$ & 74 & 3.76 \\
\hline Other external tests & 484 & $382(78.93 \%)$ & 74 & 7.85 \\
\hline Laboratory tests & 4057 & $1369(33.74 \%)$ & $60 / 98^{*}$ & 25.71 \\
\hline Referrals and interconsultations & 2225 & $1062(47.73 \%)$ & 60 & 17.7 \\
\hline Visits & 1891 & $895(47.33 \%)$ & 60 & 14.92 \\
\hline Complementary tests & 170 & $149(87.65 \%)$ & 60 & 2.48 \\
\hline Interconsultations & 160 & $16(10 \%)$ & 60 & 0.27 \\
\hline Exploration and function testing rooms & 4 & $2(50 \%)$ & 60 & 0.03 \\
\hline Total & 19.381 & $13.553(69.93 \%)$ & & 266.83 \\
\hline
\end{tabular}

*It was considered that it took 60 seconds to do $80 \%$ of requests and 98 seconds for the remaining $20 \%$.

\section{Calculation of time released}

The time released for physicians from administrative tasks due to the introduction of the clinical assistant has been calculated. The 13,553 requests made by clinical assistants accounted for 266.83 hours (6.67 
forty-hour workweeks). Most of these $(138.17 ; 51.78 \%)$ were in the day hospital area, mainly due to the displacement of requests for laboratory tests previously performed by the attending professional. In the outpatient consultation area, they released 103.96 work hours $(38,96 \%)$ for all the physicians in the department. Of these, almost 49 hours were released by requests for diagnostic imaging tests and around 26 hours by laboratory tests requests. Finally, surgical requests made by clinical assistants released 24.7 physicians' work hours. In economic terms, due to the per hour salary difference between professional profiles, this role change enables to reduce the cost by $56 \%$ with respect to the conventional model.

\section{Evolution over time}

The temporal analysis of the delegated tasks shows that, since the introduction of the new professional role, the physicians displaced about $80 \%$ of the requests to the clinical assistants. In October 2020 , there was a decrease of this percentage (due to an increase in the total number of requests) and a posterior recovery during the following months, until representing up to $72.5 \%$ in February 2021. No differences are observed in the evolution of the proportion according to the type of requests made by clinical assistants.

Figure 1. Evolution of the proportion and number of requests made by the clinical assistants.

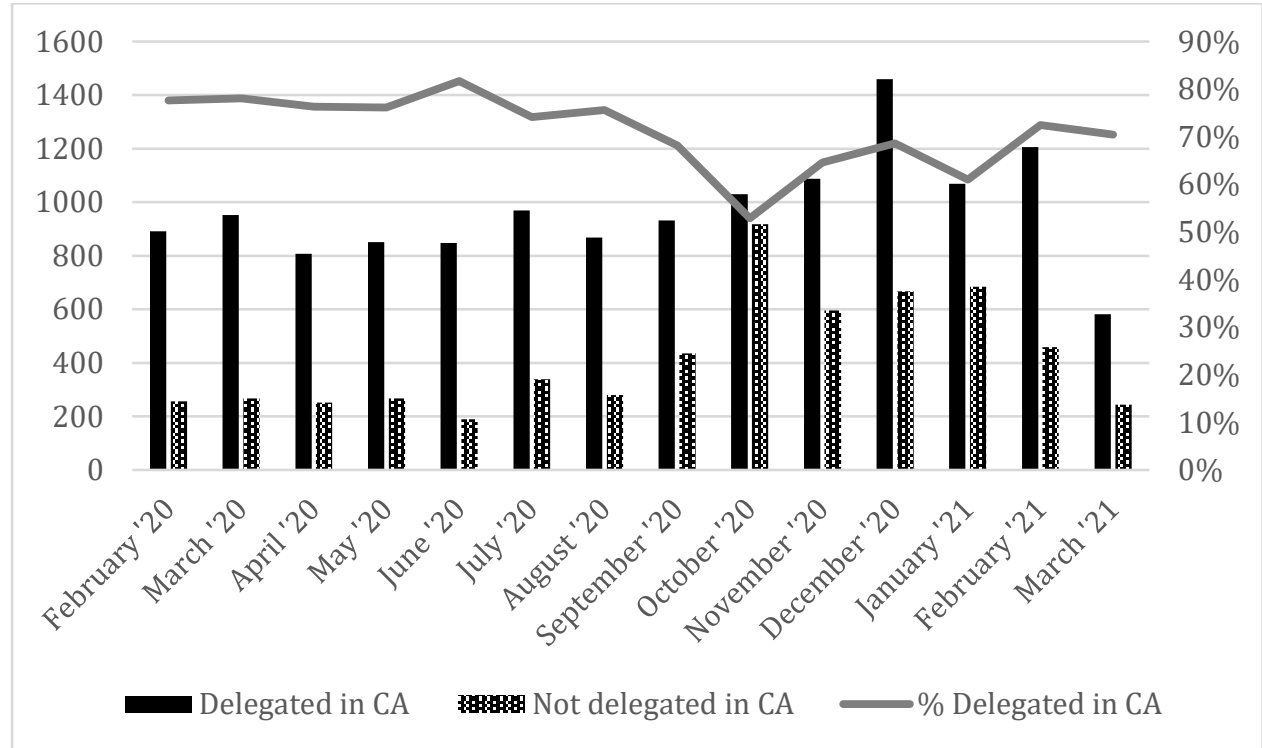

* Data is only available until mid- March 2021, this is why this month's total number of requests is inferior to the rest

\section{Discussion}

This study shows the implementation of clinical assistants has had a positive impact in terms of their objective of displacing tasks traditionally done by physicians. Altogether, clinical assistants have performed around $70 \%$ of the requests since their implementation in the oncology department, representing a nearly 7 forty-hours workweek saving.

It can be observed that some of the request types that have shifted the most are those that imply a more administratively complex process, such as surgical requests, external tests, MRIs or CT scans. In contrast, the types of procedures that physicians continue to perform the most are outpatient consultation laboratory tests, visits and interconsultations. This could be due to the fact that these are less complex requests and, therefore, physicians have a lower incentive to delegate them. The area where this new professional role has been best implemented has been in the day hospital, where they have made a very 
high percentage of requests during the entire analyzed period. Likewise, clinical assistants have made significant proportion of surgical requests.

It should be noted that the objective of the clinical assistant is not only to reduce the care staff administrative workload, but that it has also had an impact on the oncology department as a whole in organizational terms: it has improved the team cohesion , the assistant being the liaison professional for the different team members, the reference point among the professionals for queries and changes management, and the person who manages the processes, obtaining greater coordination and follow-up. During the course of this study, it has been observed that they provide more than a hundred times a month in situ attention to families and exchange more than 30 monthly e-mails with them, mainly to deal with requests for rescheduling, solve doubts about schedules and, to a lesser extent, to provide information on changes in the patient's evolution, resolve doubts about treatments and attend to requests for reports and documentation. They also exchange e-mails with internal staff and attend phone calls, mainly about scheduling, rescheduling and test follow-up. Moreover, during the first seven months since their arrival, the assistants solved 20 scheduling incidents. Therefore, it can be argued that one of the clinical assistant' objectives has been accomplished: to improve the quality of the relationship between the hospital and the patient and his or her family, insofar as he or she becomes the reference professional of families for both administrative and care issues.

Even though new roles are sometimes not well accepted by existing staff in the team [14, 18, 19-21], a satisfaction survey conducted specifically in the oncology department shows that physicians are satisfied with the new role introduction. Physicians particularly appreciate the reduction in consultation time and the improvement in the quality of consultations, and that this reduction in time spent on administrative tasks allows them to devote themselves to other care activities, as well as to research. In terms of efficiency, this role change allows to optimize the clinical process reducing the cost by $56 \%$ in relation to the conventional model.

The clinical assistants' introduction at the Sant Joan de Déu Children's Hospital is part of an institutional strategy, one of the objectives being to ensure that all professionals act to the best of their abilities. This is a step forward for healthcare teams to make the best use of their experience and knowledge, so that more specialized skills and competencies are appropriately reserved for more complex needs [20]. As OECD states, "Only with the right numbers of health workers, equipped with the right skills and providing services in the right places, will it be possible to respond equitably and effectively to the changing health needs of ageing populations" [13]. The incorporation of the clinical assistant goes in this direction, allowing physicians to focus on the care tasks for which they have unique training and experience, while administrative staff also increase their competencies, performing more complex bureaucratic and administrative tasks and further interacting with patients and their families, empowering them in the decision-making. This model change has a direct impact on care, as patients benefit from higher quality care, focused on the clinical practice.

\section{Limitations}

The study has some limitations. The database may present errors due to mistakes in the electronic medical record data introduction that may result in requests being incorrectly coded. This may have some impact on both the requests that have been included in the study and those that have been excluded, as well as on the subsequent division between the day hospital area and the outpatient consultation area. In addition, this article might have not detected all the requests that are not yet made by clinical assistants in this area. In this case, the results would been even more positive of the advantages and capabilities of the clinical assistants. 


\section{Conclusion}

The implementation of the clinical assistant' analysis shows that this new professional role has been able to make $69.93 \%$ of the requests. They made $74.25 \%$ of the outpatient surgical requests in the oncology department, $87.5 \%$ of the day hospital requests and $54.13 \%$ of the total requests in the outpatient consultation area. This study suggests that the introduction of clinical assistants in the oncology department has a great impact and is efficient as it displaces good part of the bureaucratic tasks previously performed by the health care professionals. As a result, this task delegation implies that both of them act more closely to the best-of-their-abilities and the physicians have more time available for more value-added tasks. Altogether, this results in an excellent and patient-focused higher quality care and a significant cost reduction in relation to the conventional model.

\section{References}

1. Avanzas Pablo, Isaac Pascual and César Moris. The great challenge of the public health system in Spain. $J$ Thorac Dis. 9(Suppl 6) (2017): S430-S433. doi:10.21037/jtd.2017.04.59

2. López Mejía, Mariana. "Informe de remuneración económica y satisfacción profesional: España". Medscape.com. (2019) Available on https://espanol.medscape.com/diapositivas/59000110\#1

3. Yan, Qi, Zheng Jiang, Zachary Harbin, Preston H. Tolbert and Mark G. Davies. "Exploring the relationship between electronic health records and provider burnout: A systematic review." Journal of the American Medical Informatics Association. 28.5 (2021): 1009-1021. https://doi.org/10.1093/jamia/ocab009

4. Rotenstein, Lisa S., Matthew Torre, Marco A. Ramos, Rachael C. Rosales, Constance Guille, Srijan Sen and Douglas A. Mata. "Prevalence of Burnout Among Physicians: A Systematic Review". JAMA. 320.11 (2018): 1131-1150. doi:10.1001/jama.2018.12777

5. Woo, Tiffany, Roger Ho, Arthur Tang and Wilson Tam. "Global prevalence of burnout symptoms among nurses: A systematic review and meta-analysis. Journal of Psychiatric Research. 123 (2020): 9-20. https://doi.org/10.1016/j.jpsychires.2019.12.015

6. Edwards, Samuel T., Christian D. Helfrich, David Grembowski, Wlizabeth Hulen, Walter L. Clinton, Gordon B. Wood, Linda Kim, Danielle E. Rose and Greg Stewart. "Task delegation and burnout trade-offs among primary care providers and nurses in Veterans Affairs Patient Aligned Care Teams (VA PACTs)." The Journal of the American Board of Family Medicine 31.1 (2018): 83-93.

7. Ribelles, N., I. Álvarez-López, A. Arcusa, J. I. Chacón, J. de la Haba, J. García-Corbacho, J. Garcia-Mata, C. Jara, J. M. Jerez, M. Lázaro-Quintela, L. Leon-Mateos, N. Ramírez-Merino, A. Tibau and A. Garcia-Palomo. "Electronic health records and patient registries in medical oncology departments in Spain". Clinical and Translational Oncology. (2021). https://doi.org/10.1007/s12094-021-02614-9

8. Beech Jake, Bottery Simon, Charlesworth Anita, Evans Harry, Gershlick Ben, Hemmings Nina, Imison Candace, Kahtan Pinchas, McKenna Helen, Murray Rrichard and Palmer Billy. Closing the gap. Key areas for action on the health and care workforce. The Health Foundation, The King's Fund, Nuffiled Trust. (2019) 


\section{PIAAC Survey (cited in OECD)}

10. NHS Providers. "There for us. A better future for the NHS workforce". (2017). Available on https://nhsproviders.org/a-better-future-for-the-nhs-workforce.

11. Hudson, Sharon M., Suzanne Roberts, Robert Jacobs, Heydeh Khalili and Mona Patel Gera. "Integration of Medical Scribes in a General Pediatric Outpatient Clinic: Pilot Results Studying Provider Satisfaction". Perspectives in Health Information Management. (2020) 1-11. https://perspectives.ahima.org/integration-of-medical-scribes-in-a-general-pediatric-outpatient-clinicpilot-results-studying-provider-satisfaction/

12. Imison, Candace, Jake Beech, Helen McKenna and Richard Murray. "5. Workforce redesign: the right teams with the right skills and technological support" In Closing the gap. Key areas for action on the health and care workforce. (2019). The Health Foundation, The King's Fund and Nuffieldtrust. Available on https://www.kingsfund.org.uk/publications/closing-gap-health-care-workforce

13. OECD. Health Workforce Policies in OECD Countries: Right Jobs, Right Skills, Right Places, OECD Health Policy Studies, OECD Publishing, (2016) Paris, https://doi.org/10.1787/9789264239517-en

14. Imison, Candace, Sophie Castle-Clarke and Robert Watson. Reshaping the workforce to deliver the care patients need. (2016). Nuffieldtrust and NHS Employers. Available on https://www.nuffieldtrust.org.uk/files/2017-01/reshaping-the-workforce-web-final.pdf

15. Altshculer, Justin, David Margolius, Thomas Bodenheimer and Kevin Grumbach. "Estimating a reasonable patient panel size for primary care physicianasw with team-based task delegation". The Annals of Family Medicine. 10.5 (2012): 396-400. https://doi.org/10.1370/afm.1400

16. Pardo Romaguera E, Muñoz López A, Valero Poveda S, Porta Cebolla S, Fernández-Delgado R, Barreda Reines MS and Peris Bonet R. “Cáncer infantil en España. Estadísticas 1980-2017”. Registro Español de Tumores Infantiles (RETI-SEHOP). Valencia: Universitat de València, 2018 https://www.uv.es/rnti/informes.html

17. Cohen, Rubin I. "Lean Methodology in Health Care". Chest. 154.6 (2018): 1448-1454. https://doi.org/10.1016/j.chest.2018.06.005

18. Russell-Babin, Kathleen and Wurmser, Teri. "Transforming care throught top-of-license practice". Nursing Management (Springhouse), 47.5 (2016): 24-28. 10.1097/01.NUMA.0000482527.15743.12

19. Cain, Cindy L., Caty Taborda and Monica Frazer. "Creating "Risky" New Roles in Healthcare: Identities, Boundary-Making, and Skilling Under Rationalization and Consumer Demand". Work and Occupations. 48.3 (2021): 353-385. https://doi.org/10.1177/0730888420983396

20. Institute of Medicine; Committee on the Robert Wood Johnson Foundation Initiative on the Future of Nursing, at the Institute of Medicine. The Future of Nursing. Leading change, Advancing Health. (2011).

21. Hoskins, Rebecca. "Evaluating new roles within emergency care: A literature review". International Emergency Nursing. 19 (2011): 125-140. https://doi.org/10.1016/j.ienj.2010.09.003 